\title{
Investigation heavy metals levels in eyebrows cosmetic in Birjand: study of lead and cadmium levels (2017)
}

\author{
Maryam Khodadadi ${ }^{1}$ [D], Hadigheh Dorri' ${ }^{1}$ (D), Abbas Ali Ramazani ${ }^{2}$ (D), \\ Marzieh Edalatian $^{3}$, Aghdas Maleki ${ }^{3}$ (iD), Zahra Assari ${ }^{3}$ ic \\ ${ }^{1}$ Corresponding author; Social Determinants of Health Research Center, Birjand University of Medical Sciences, Birjand, Iran. \\ Tel: +985632381661 Fax: +5631631651 Email: maryam.khodadadi@gmail.com \\ ${ }^{2}$ Social Determinants of Health Research Center, Department of Public Health, Birjand University of Medical sciences, Birjand, \\ Iran \\ ${ }^{3}$ Student Research Committee, Birjand University of Medical Sciences, Birjand, Iran.
}

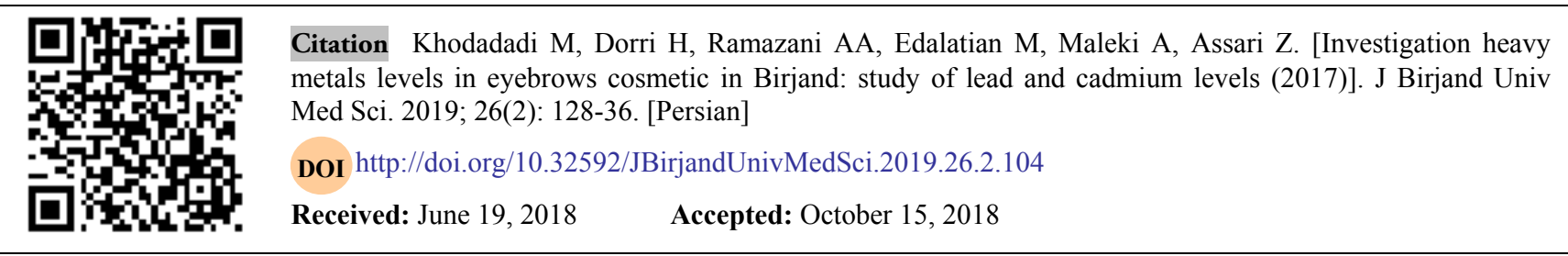

\begin{abstract}
Background and Aim: Heavy metals such as lead and cadmium are toxic and carcinogenic compounds that are absorbed through the skin. Therefore, the aim of this study was to determine the amount of lead and cadmium heavy metals in bulk branded cosmetic bags (mascara and tattoo) distributed in Birjand.

Materials and Methods: In this descriptive-analytical study, by referring to the Birjand cosmetics and health center union and by using a simple random sampling method, the 12 centers are selected and by referring to them, 63 samples of mascara and eyebrow tattoos were selected. Due to the limited number of eyebrow cosmetics brands, all existing brands were sampled. The lead and cadmium levels of the samples were determined using acid digestion and atomic absorption. Data were analyzed using statistical tests of Kruskal-Wallis and Mann-Whitney.
\end{abstract}

Results: The mean lead concentration in mascara and tattoos was 51.8-227.4 $\mu \mathrm{g} / \mathrm{g}$ and $37.5 \pm 313.6 \mathrm{mg} / \mathrm{g}$, respectively, and in all samples, the concentration of cadmium was zero. There was a significant difference among the different tattoo samples in terms of concentration of lead $(\mathrm{P}<0.05)$, but there was no significant difference between mascara samples $(\mathrm{P}=0.761)$.

Conclusion: Due to unauthorizedly, the concentration of lead heavy metal in conventional cosmetic products and also no significant difference among famous brands, sufficient awareness of the risk of large amounts of such substances is necessary.

Key Words: Heavy Metals; Lead; Cadmium; Eyebrow; Cosmetic 


\title{
بررسى مقدار فلزات سنكين در لوازم آرايشى ابرو

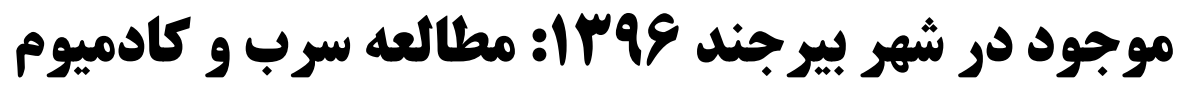

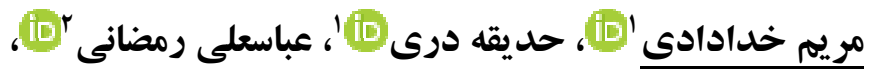

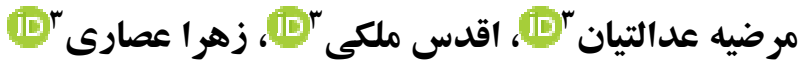

جككيله

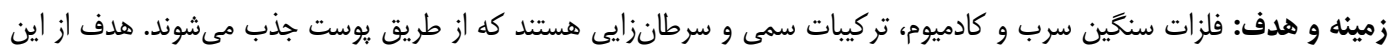

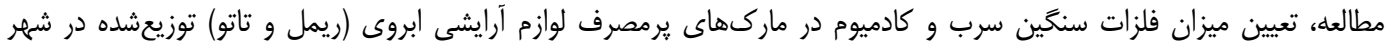

بيرجند بود.

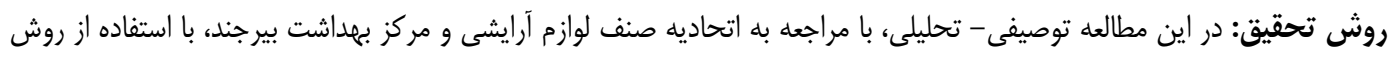

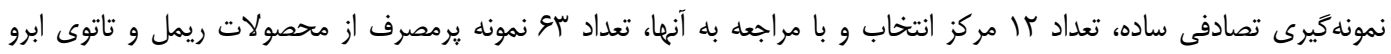

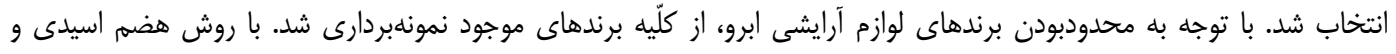

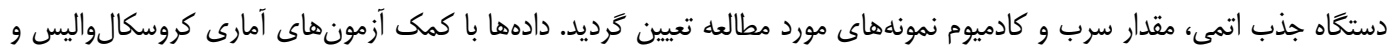

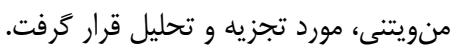

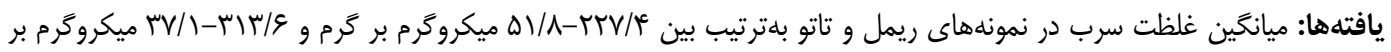

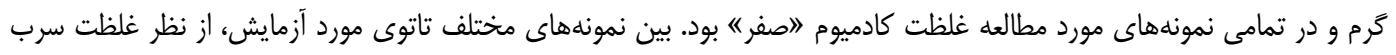

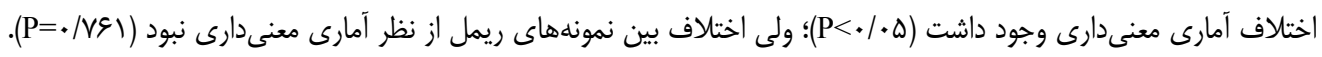

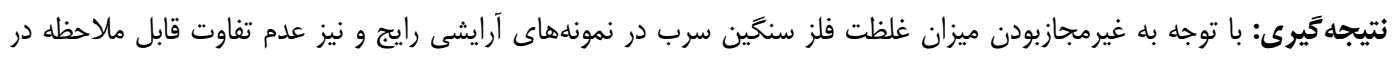

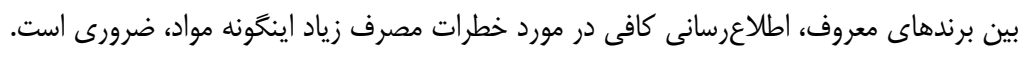

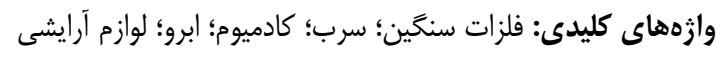

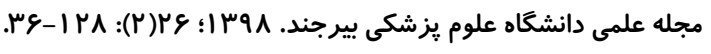
دريافت: 
براى طبقات متوسط و يايين جامه رايج شده است. در طول

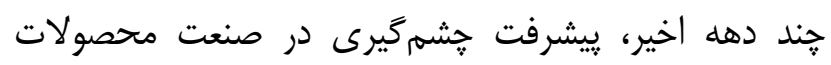

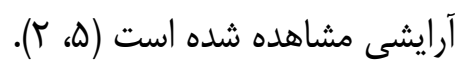

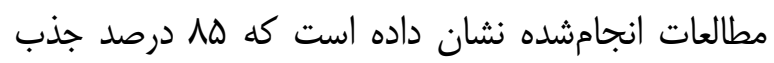

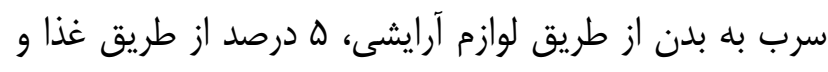

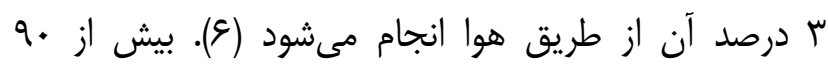

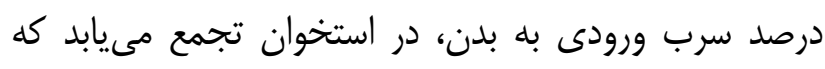

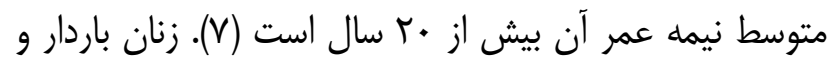

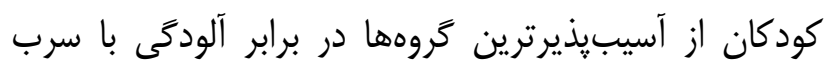

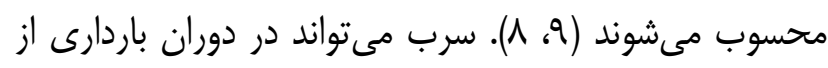

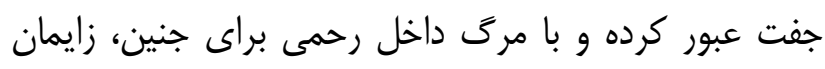

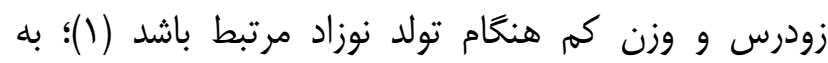

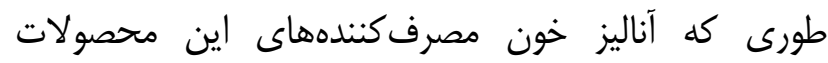

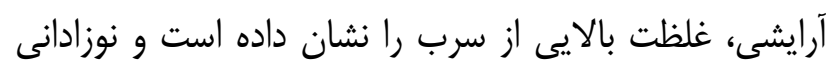

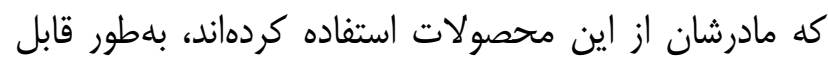

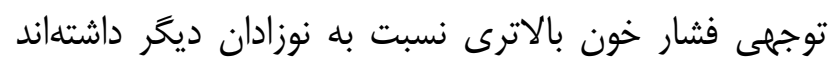

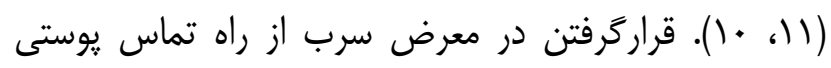

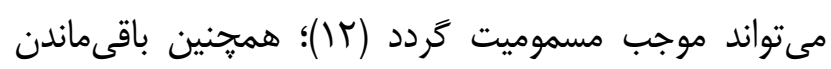

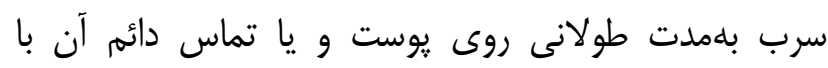

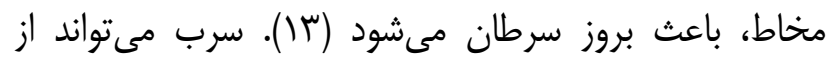

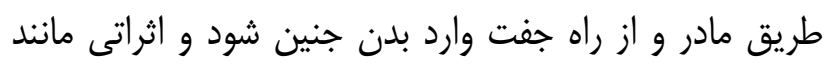

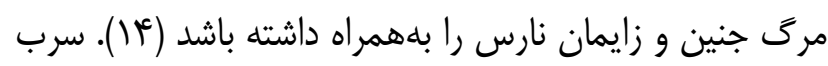

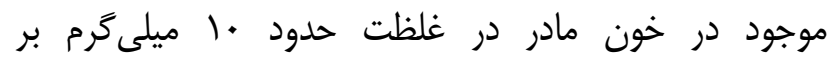
دسىليتر، با افزايش خطراتى مانند: فشار خون دورد دوران بان باردارى، سقط جنين و كاهش عملكرد سيستم عصبى نوزادان همراه

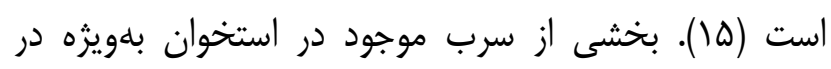

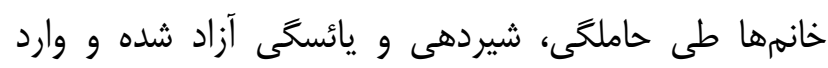

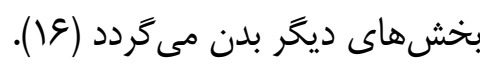

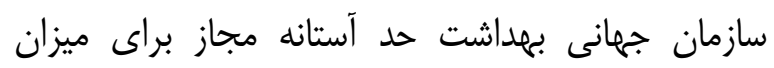

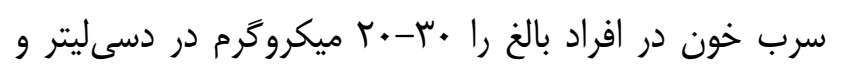

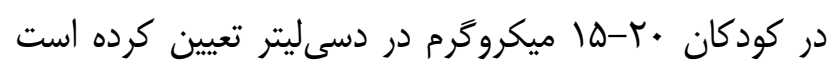

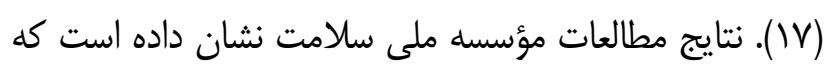

مقلدمه

فلزات سنگحين از جمله آلايندههايى هستند كه حضور آنها

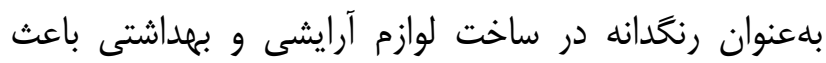

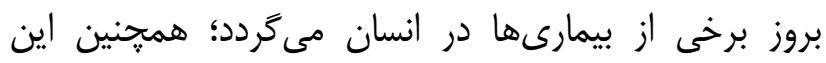

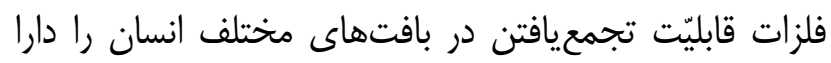

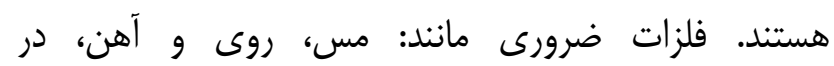

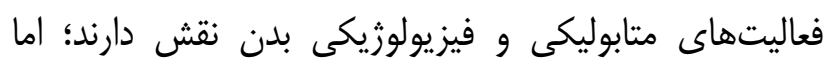

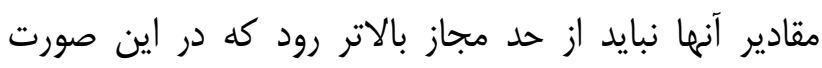

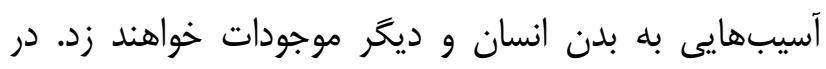

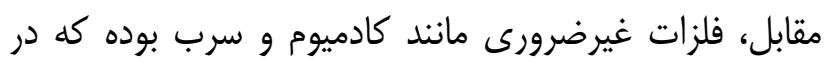

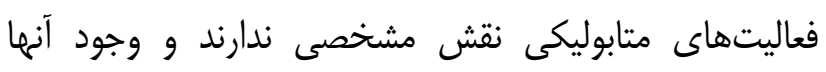

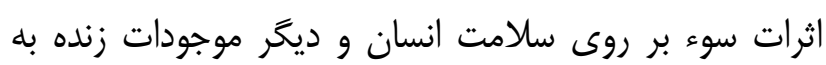

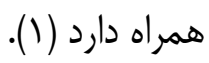
مواد خام برخى صنايع مثل صنايع ساخت وسايل آرايشى الرى و بهداشتى، حاوى فلزات سنخين است. فلزات كادميوم و سرب از آلايندهاى معمول زيستمحيطى هستند كه در در

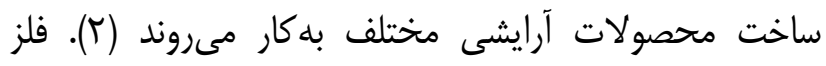

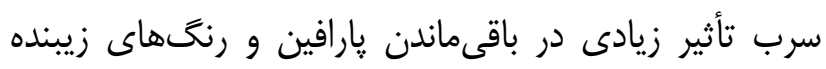

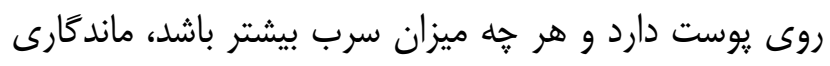
رنخ روى يوست نيز بيشتر مىشود (1). مصرف بهرويه لوازم

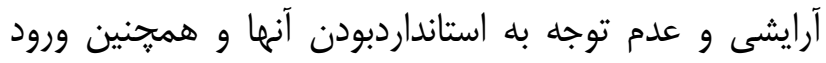
اين محصولات بلهصورت تقلبى و غير مجاز به كشور از استانهاى مرزى كه بهراحتى با قيمت پايين در اختيار مردم

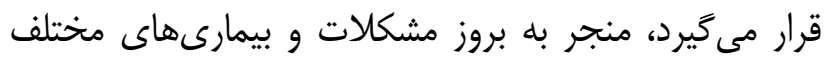

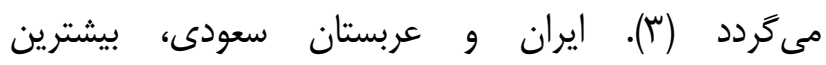

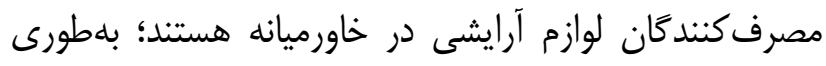

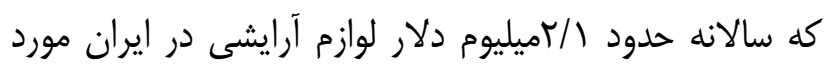

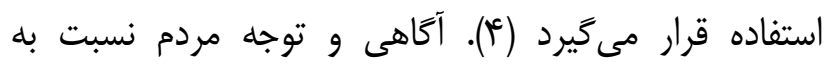

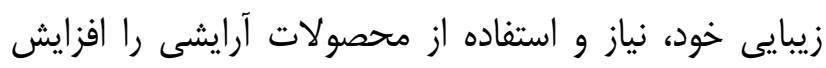

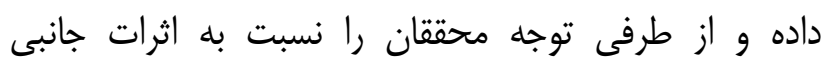

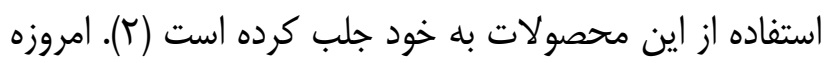
استفاده از لوازم آرايشى نهتنها توسط طبقه باته بالاى جاد جلب كرده است بلكه 
با توجه به اينكه تاكنون مطالعه مشابهى در مورد تعيين

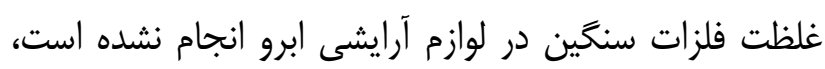

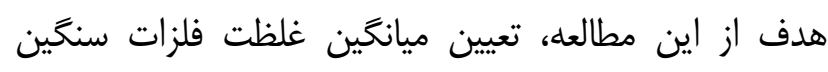

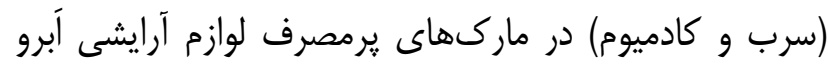

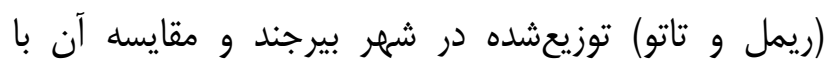
استانداردهاى موجود در اين زمينه بوده است.

\section{روش تحقيق}

اين مطالعه توصيفى - تحليلى، در سال عوسبا بلهصورت

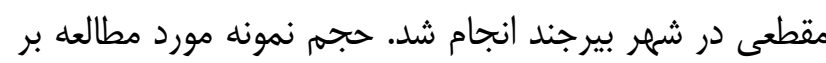
اساس فرمول

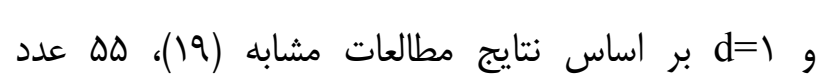

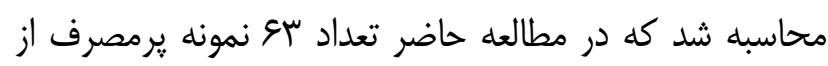

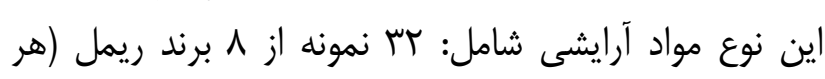

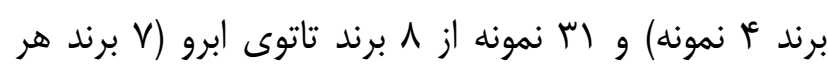

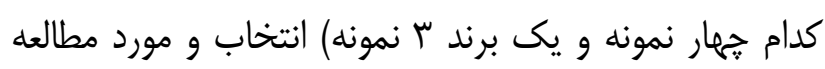

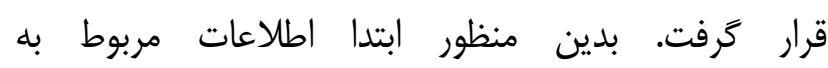

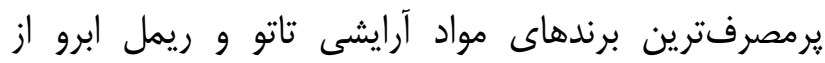

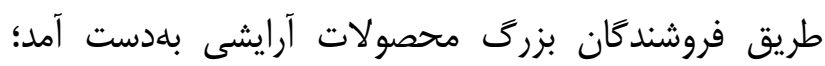

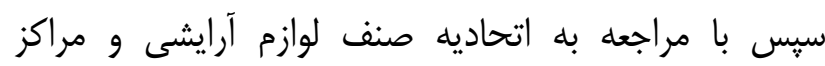
بهداشت شهر بيرجند، مراكز عرضه لوازم آرايشى ابرو لواديه شناسايى و با استفاده از روش نمونه ئيرى تصادفى ساده تعداد

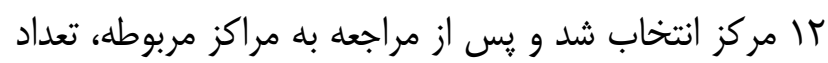

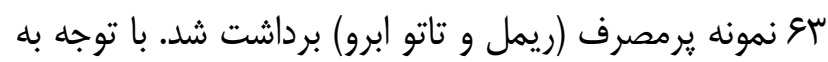

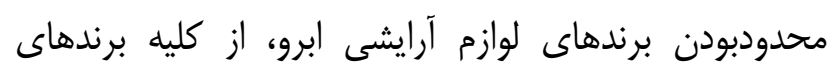
موجود در سطح شهر نمونهبردارى شد.

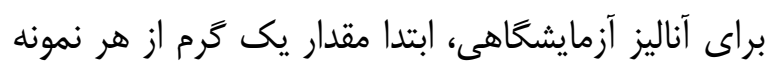

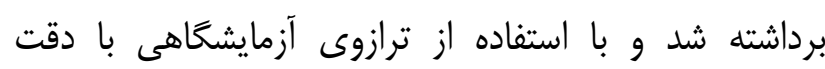

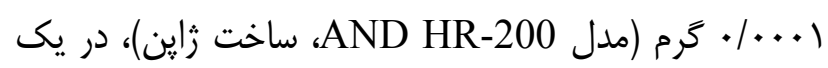

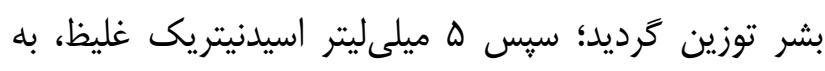

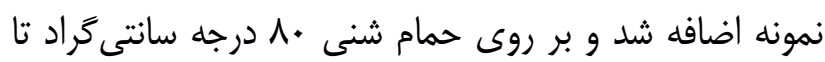

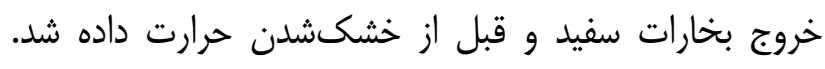

فلزات سنَّين موجود در لوازم آرايشى مىتواند از طريق جذب يوستى، آلرزى بوستى بلهوجود بياورند (1).

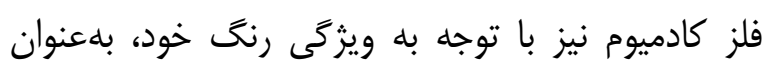
رنحدانه رنكى در خيلى از محصولات آرايشى مورد استفاده

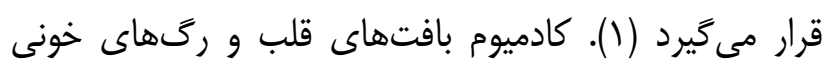

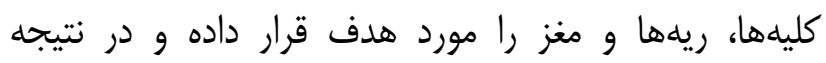
بيمارىهاى قلبى، فشار خون، آسيب كبدى و تضعيف سيستم

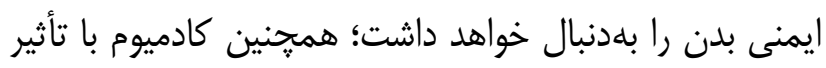

بر متابوليسم كلسيم، باعث تخريب استخوان مىشود (1).

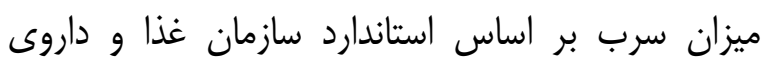

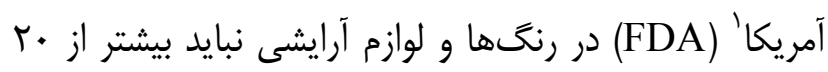

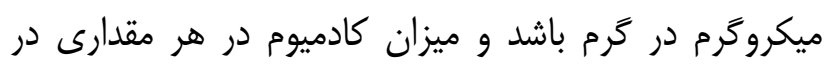
مواد آرايشى بر اساس اين استاندارد ممنوع شده است (1) (1). بر اساس مطالعه وحيد دستجردى و همكاران در مورد

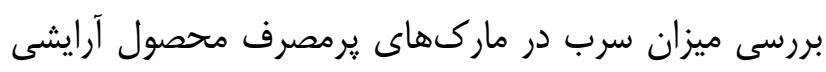

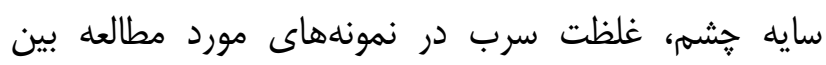

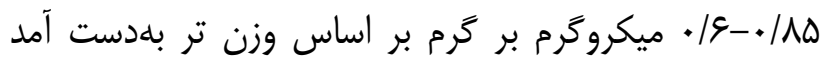

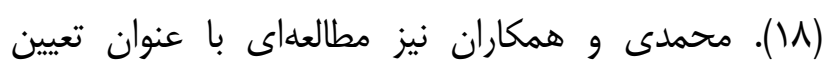

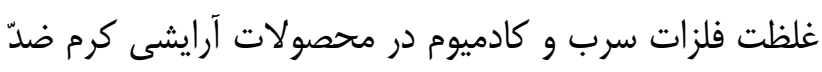

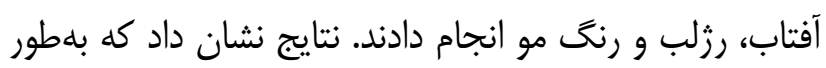

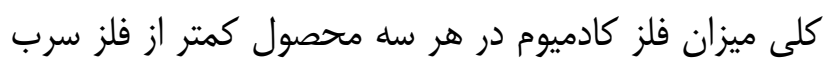

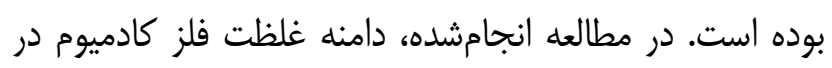

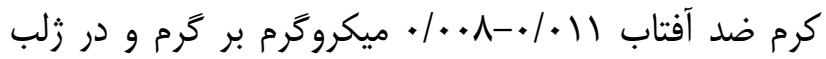

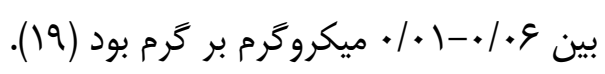
در بررسى ميزان سرب در رزلبهاى مايع و و جامد برم برد

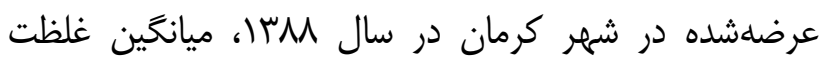

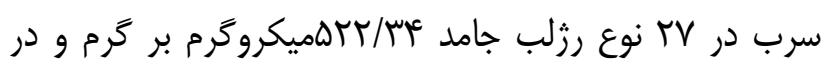

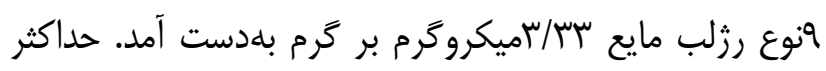
ميزان سرب در نمونهاى مورد بررسى بلميزان

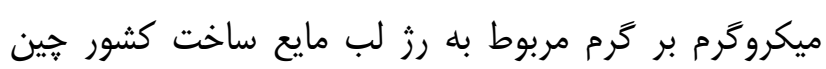
بود (·r).

\footnotetext{
${ }^{1}$ Food and drug Administration
} 
ابرو در نمودار يك آمده است. بر اساس نتايج بلهدست آمده،

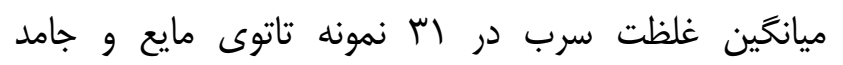

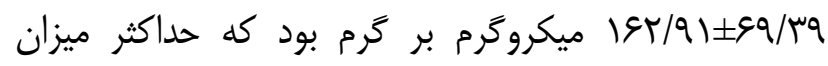

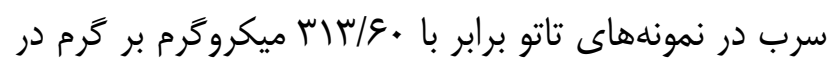

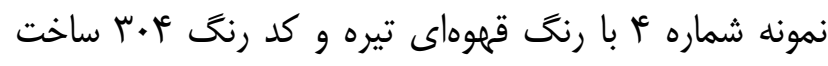

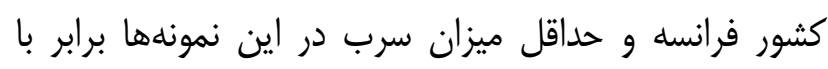
.

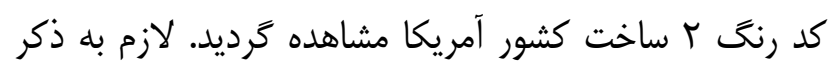
است كه غلظت كادميوم در تمامى نمونههاى ريمل و تاتوى ابروى مورد مطالعه 》صفر " بهدست آمد.

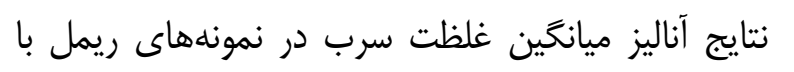

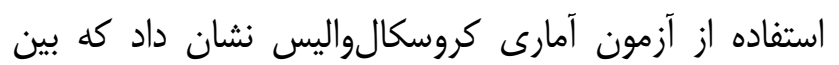

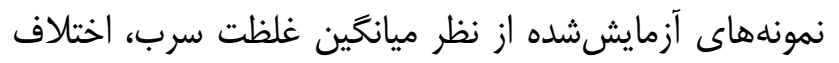

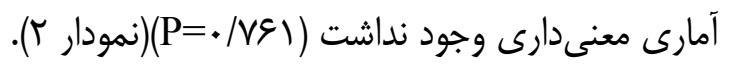

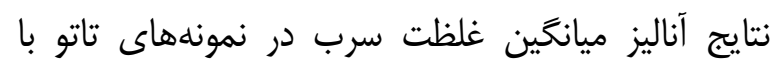

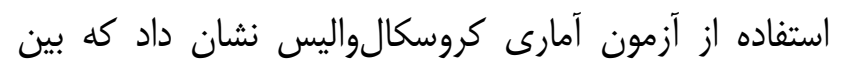

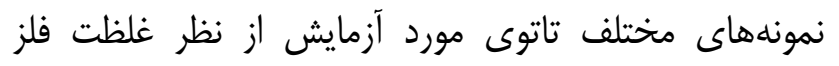

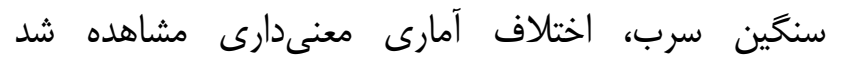
و اين اختلاف، بين برند شماره ع با ساير برندها

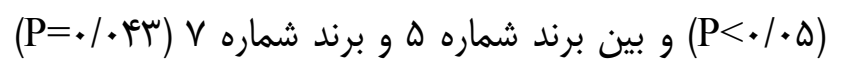

$$
\text { وجود داشت (نمودار ()). }
$$

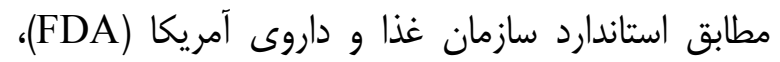

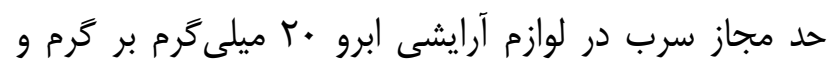

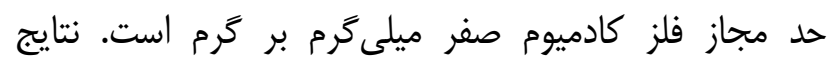

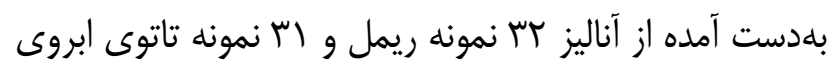

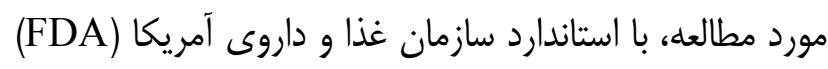

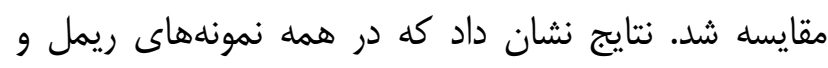

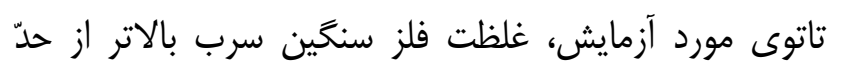

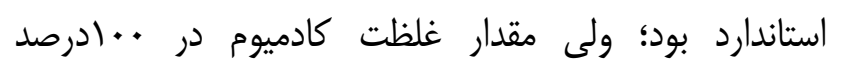
نمونهها مطابق با استاندارد بود.

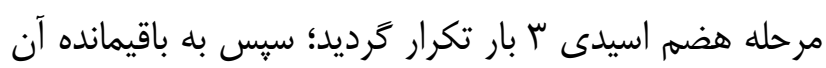
در بشر، • ا ميلىليتر آب مقطر افزوده و محتواى بشر از فيلتر

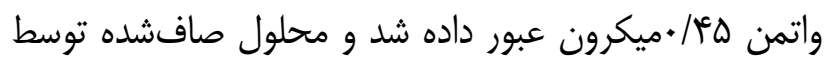

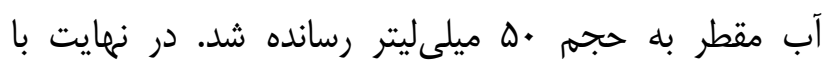

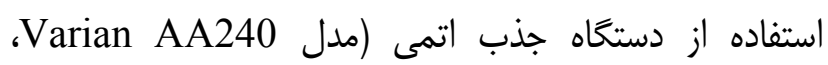

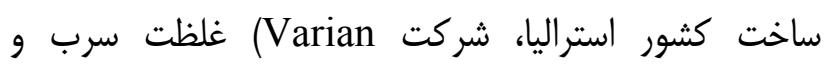

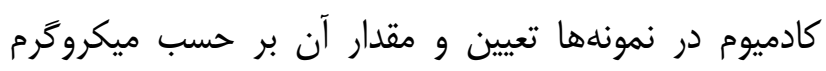

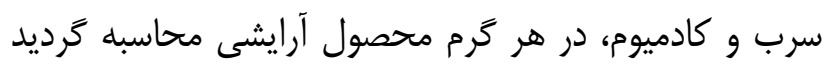

نتايج بلهدست آمده، با استانداردهاى معاونت غذا و داروى

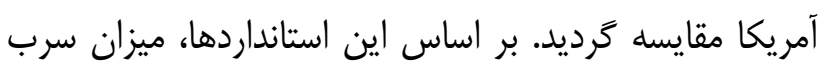

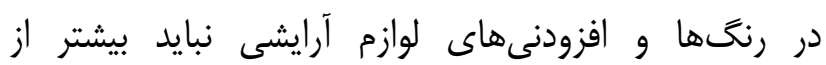

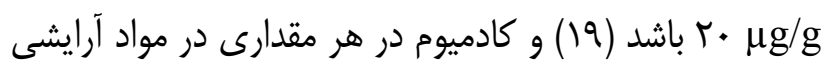

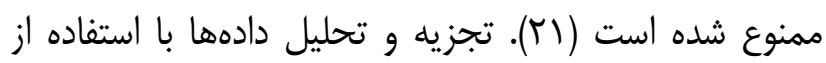

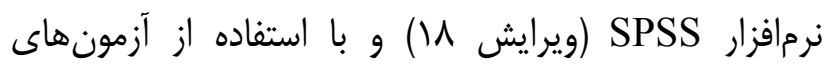

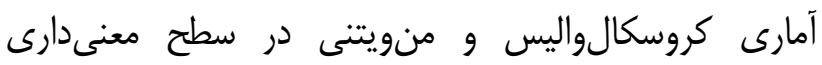

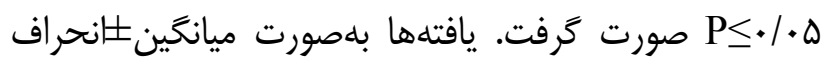

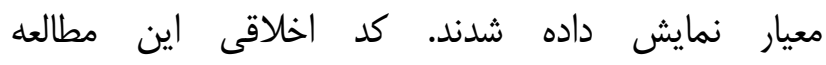
Ir.bums.REC.1396.2

\section{يافتهها}

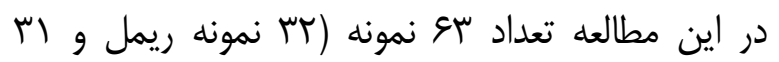

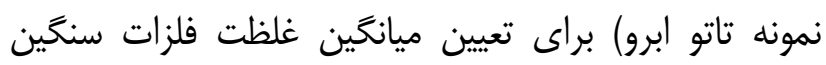
سرب و كادميوم مورد آزمايش قرار كَرفت. بر اساس نتين نتايج،

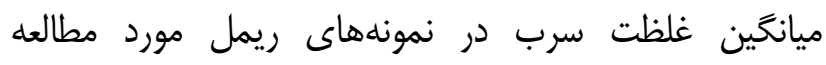
.

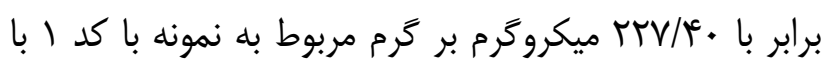

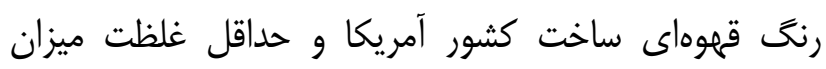

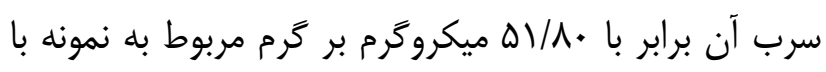
كد ب. با رنخ قهوهاى ساخت كشور جين بود.

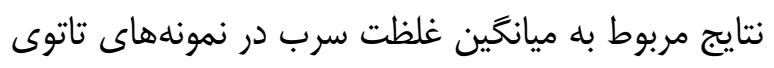




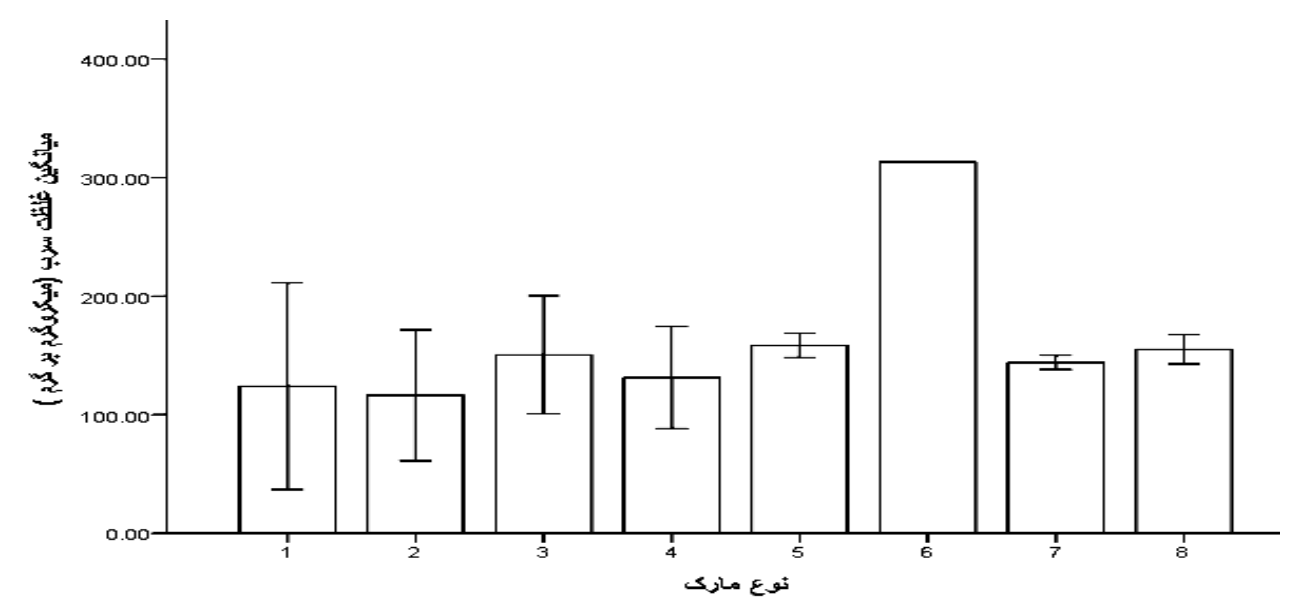

نمودار ا - مقايسه ميانكَين غلظت سرب (ميكروترم بر ترم) در برندهاى مختلف تاتوى ابروى توزيعشده در شهر بيرجند

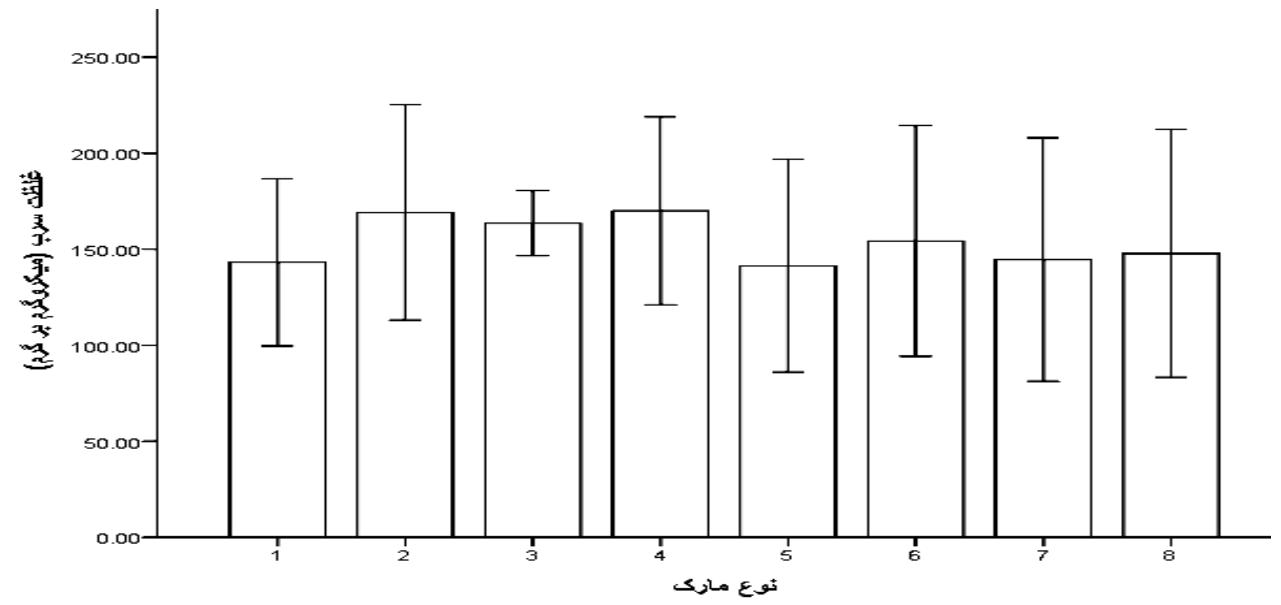

نمودار r- مقايسه ميانكَين غلظت سرب (ميكروترم بر ترم) در برندهاى مختلف ريمل ابروى توزيعشده در شهر بيرجند

نتايج اين مطالعه نشان داد كه غلظت سرب در نمونههاى

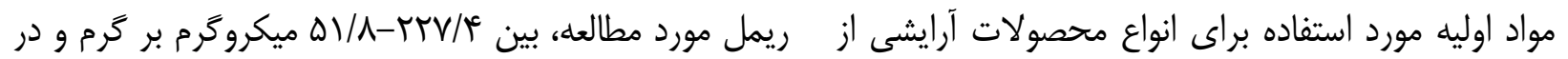

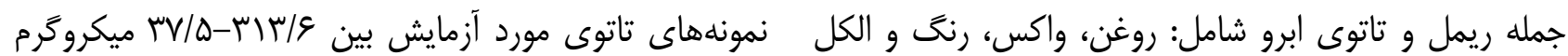

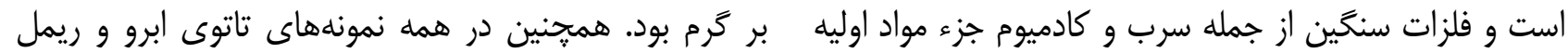

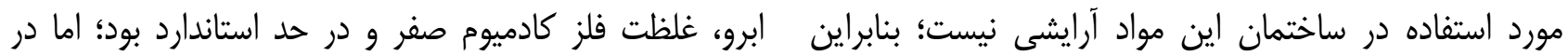

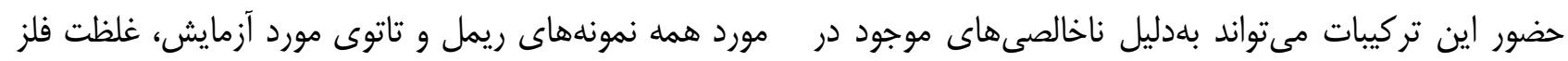

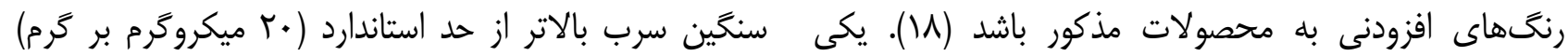

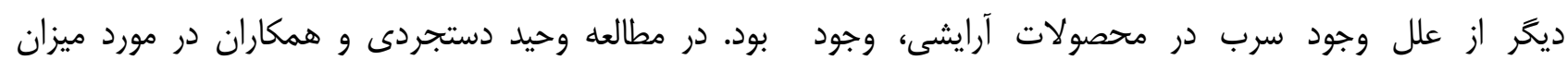

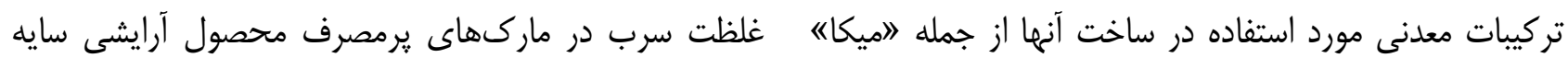

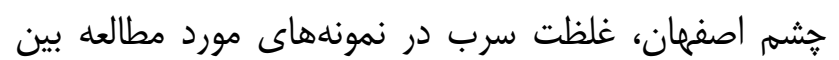

است كه ممكن است حاوى سرب باشد (l). 
صورتى كه ميانخين غلظت سرب در سو نمونه مورد بررسى در

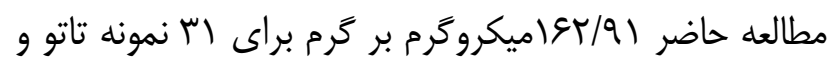
א

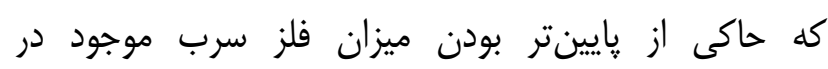

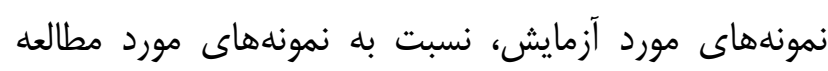
توسط ملكوتيان و همكاران بوده است (· (r).

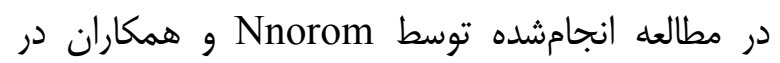
سال ه +.r بر روى محصولات خط خشمه و مداد جشهم، ميزان

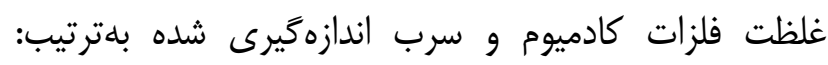

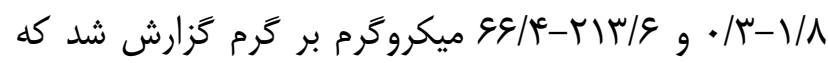
از نتايج حاصل از اين مطالعه كمتر است (r). در مطالعه حاضر

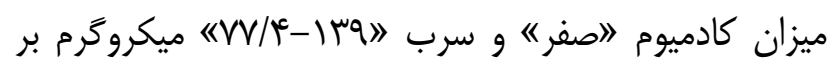

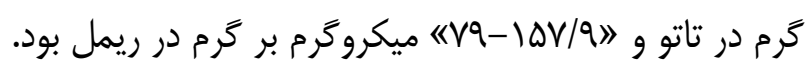
در مطالعه انجامشده توسط Volpe و همكاران در سال

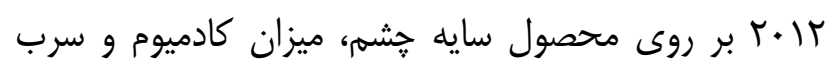

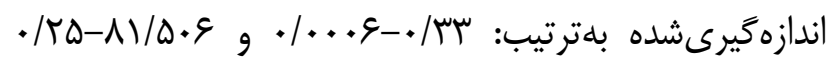

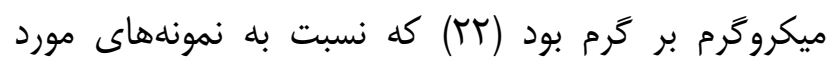
مطالعه در يزوهش حاضر كمتر است. در مطالعه حاضر ميزان

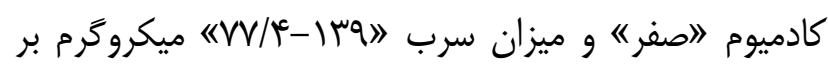

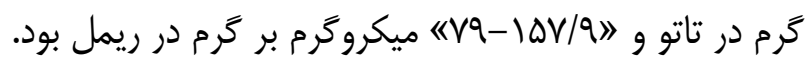

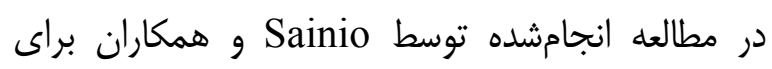

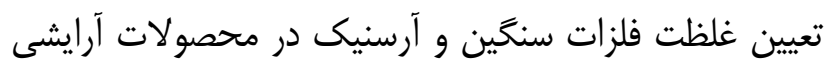
سايه جشم مشخص شد كه بالاترين غلظت سرب اب در و

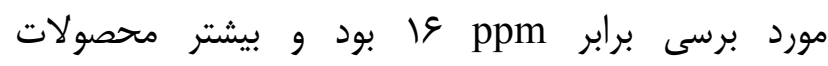
آزمايششده حاوى مقاديرى سرب بودند كه مقدار آن از نتايج

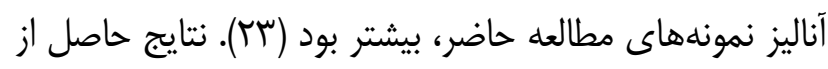

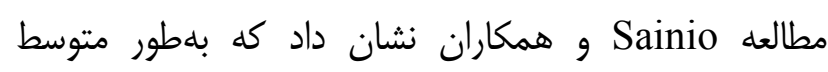
غلظت سرب در نمونههاى جامد بيشتر از نمونههاى مايع

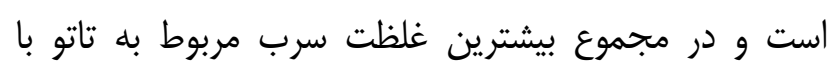

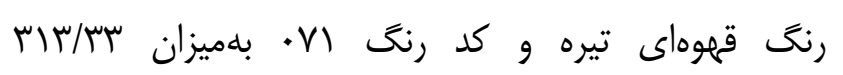

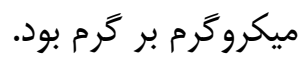
نتايج مطالعه Al-dayel و همكاران در مورد سنجش

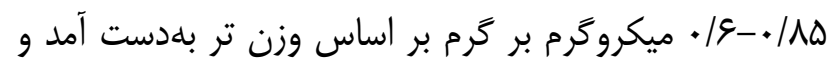

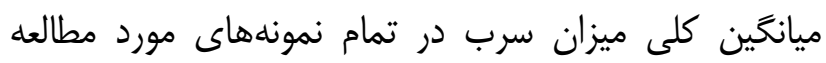

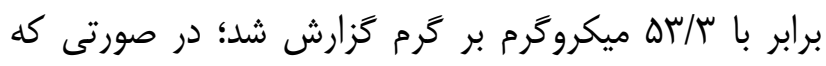

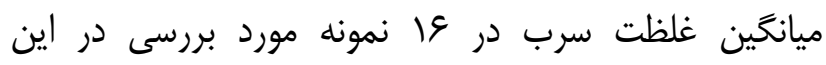

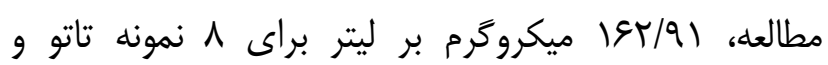

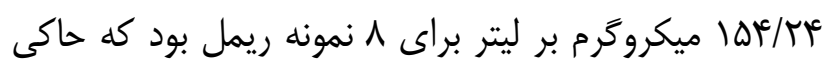

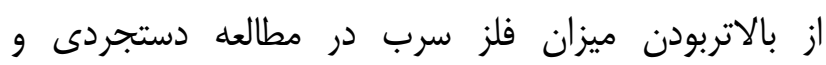
همكاران است (1) (1).

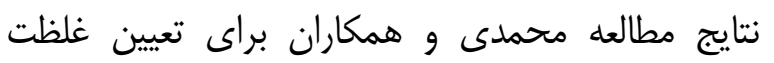

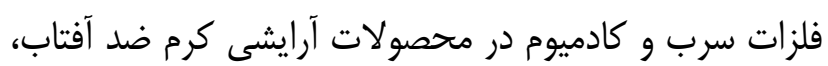
رزلب و رنگ مو نشان داد كه ميزان فلز كادميوم در هر سه سه محصول كمتر از فلز سرب بود. در مطالعه بيانشده، دامنه دئه

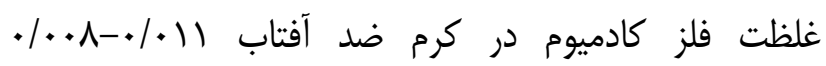

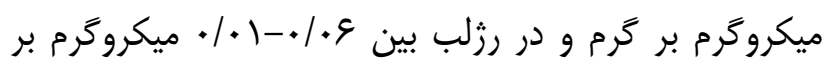

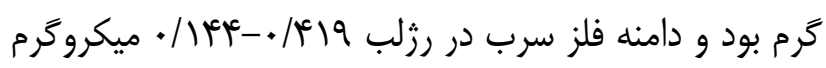

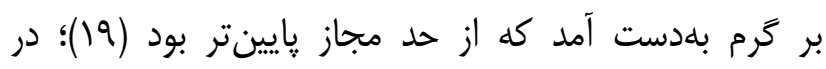

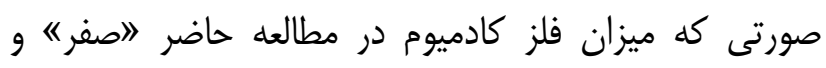

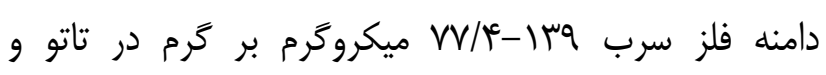

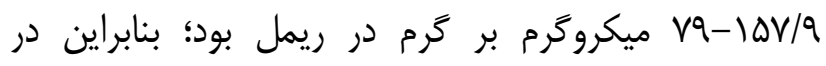

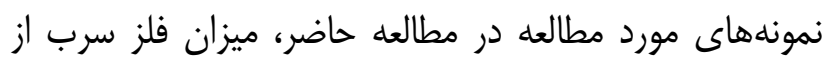

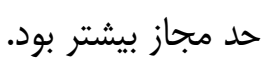
در بررسى ميزان سرب موجود در رزلبهاى مايع و جامد عرضهشده در شهر كرمان در سال شMrا توسط ملكوتيان و

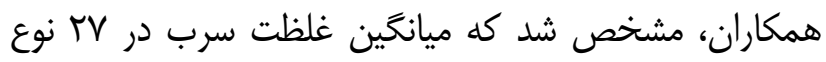

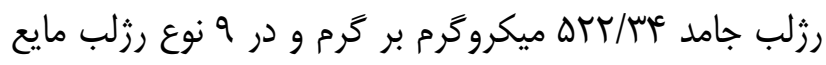

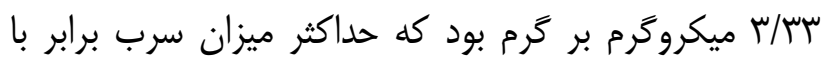
ماق

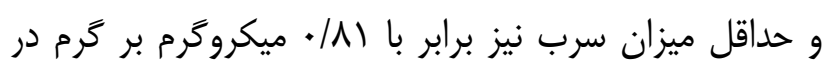
رزلبهاى ساخت كشور جين و نمونههاى ديخر از كشور

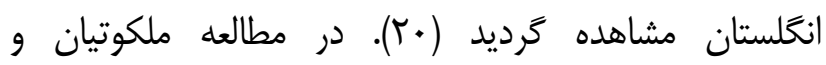

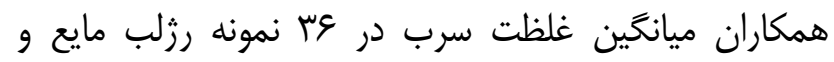

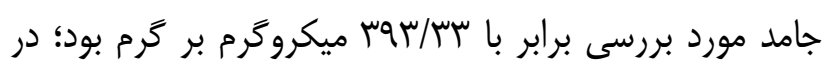




\section{نتيجه كيرى}

در اين مطالعه ميزان سرب در نمونههاى ريمل و تاتوى

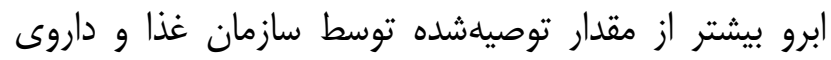

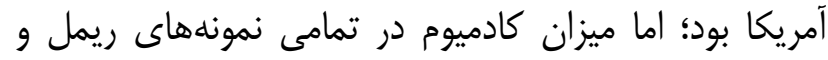

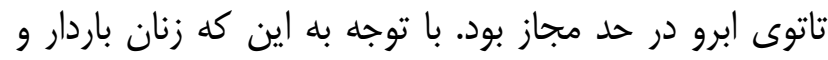

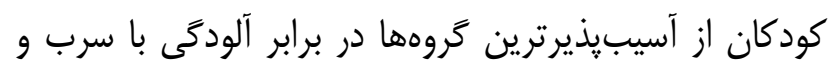

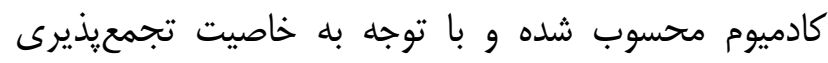

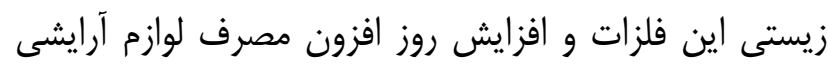

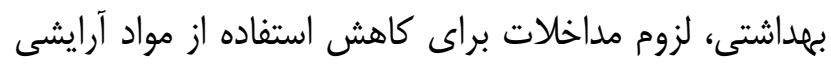

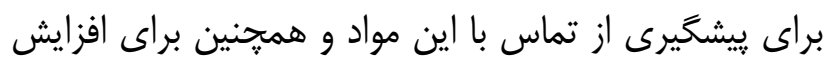

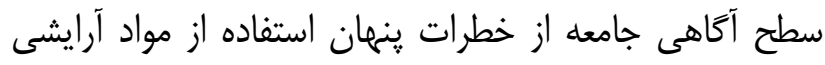
بلهضوص در قشر جوان حس مى جود.

\section{تقدير و تشكر}

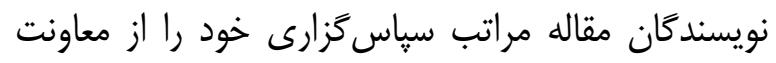
تحقيقات و فناورى دانشگاه علوم يزشكى بيرجند براى تأمين منان

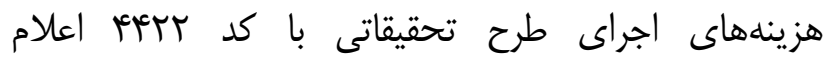
مىنمايند.

تضاد منافع:نويسندكان مقاله ابراز مى دارند كه در يثوهش

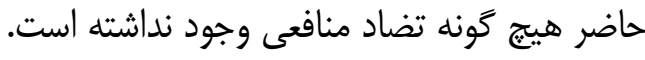

غلظت فلزات سنخين در محصولات آرايشى- بهداشتى صورت نشان داد كه غلظت سرب در نمونههاى مورد مطالعه

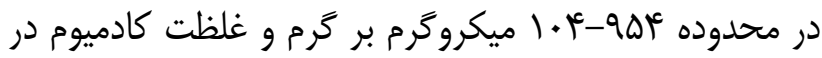

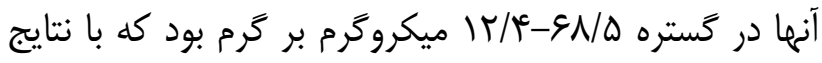
مطالعه حاضر متفاوت است (بآ). دليل وجود اين اختلافات در مطالعات متعدد مىتواند

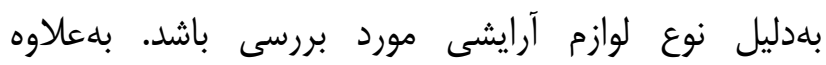
محصولات آرايشى ساخت كشورهاى مختلف غلغ نلظتهاى

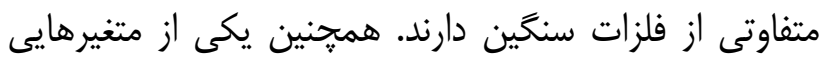

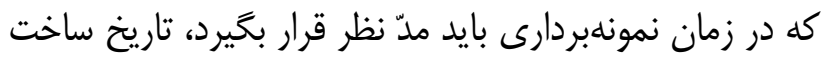
محصول مورد بررسى است كه بايستى مورد توجه قرار گيرد. با توجه به اينكه لوازم آرايشى - بهداشتى در ايران به بهمقدار

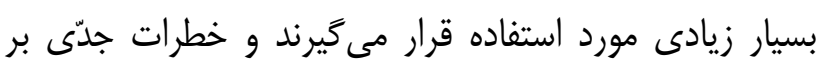

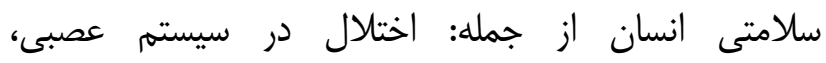
بيمارىهاى قلبى- عروقى و كليوى و حتى انواع سرطانها

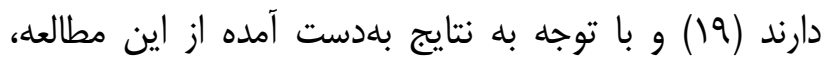

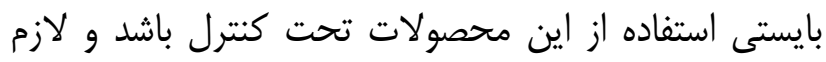

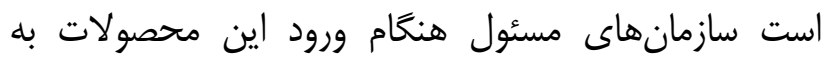

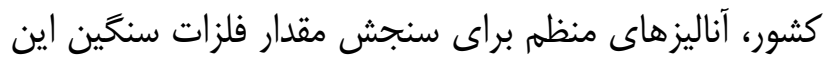

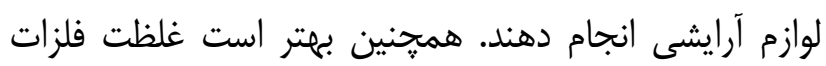

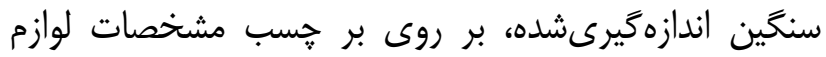

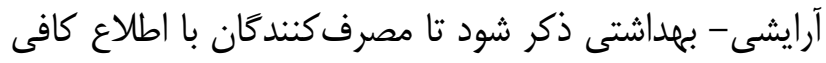
محصول مدّ نظر خود را انتخاب نمايند.

1- Mansouri B, Maleki A, Mahmoodi M, Davari B, Shahsavari S. Risk Assessment of Heavy metals in lipstick and hair dye cosmetic products in Sanandaj. J Kurdestan Univ Med Sci. 2017; 22(3): 31-9. [Persian]

2- Nnorom IC, Igwe JC, Oji-Nnorom CG. Trace metal contents of facial (make-up) cosmetics commonly used in Nigeria. Afri Biotechnol. 2005; 4(10): 1133-8. DOI: 10.4314/ajb.v4i10.71343

3- Gondal MA, Seddigi ZS, Nasr MM, Gondal B. Spectroscopic detection of health hazardous contaminants in lipstick using laser induced breakdown spectroscopy. J Hazard Mater. 2010; 175(1-3): 726-32. DOI: 10.1016/j.jhazmat.2009.

4- Mousavi Z, Ziarati P, Shariatdoost A. Determination and safety assessment of lead and cadmium in eye shadows purchased in local market in Tehran. J Environ Anal Toxicol. 2013; 3(7): 193. DOI: 10.4172/2161-0525.1000193

5- Al-Saleh I, Al-Enazi S, Shinwari N. Assessment of lead in cosmetic products. Regul Toxicol Pharmacol. 2009; 54(2): 105-13. doi: 10.1016/j.yrtph.2009.02.005. 
6- Umar MA, Caleb H. Analysis of metals in some cosmetic products in FCT abuja, Nigeria. Int J Res Cosmet Sci. 2013; 3(2): 14-8.

7- WHO. Environmental Health Criteria 165: Inorganic Lead. 2004. INCHEM, International Programmed on Chemical Safety. Available at: https://www.who.int/ipcs/publications/ehc/en/ Accessed March 11, 2018

8- al-Saleh I, Khalil MA, Taylor A. Lead, erythrocyte protoporphyrin, and hematological parameters in normal maternal and umbilical cord blood from subjects of the Riyadh region, Saudi Arabia. Arch Environ Health. 1995; 50(1): 66-73. DOI:10.1080/00039896.1995.9955014

9- Rothenberg SJ, Schnaas L, Salgado-Valladares M, Casanueva E, Geller AM, Hudnell HK, et al. Increased ERG aand b-wave amplitudes in 7- to 10-year-old children resulting from prenatal lead exposure. Invest Ophthalmol Vis Sci. 2002; 43(6): 2036-44.

10- Al-Ashban RM, Aslama M, Shah AH. Kohl (surma): a toxic traditional eye cosmetic study in Saudi Arabia. Public Health. 2004; 118(4): 292-8. DOI: 10.1016/j.puhe.2003.05.001

11- Hardy AD, Walton R, Vaishnav R. Composition of eye cosmetics (kohls) used in Cairo. Int J Environ Health Res. 2004; 14(1): 83-91. DOI: 10.1080/09603120310001633859

12- Hardy AD, Walton RI, Vaishnay R, Myers KA, Power MR, Pirrie D. Chapter 5 Egyptian eye cosmetics ("Kohls"): Past and present. Physical Techniques in the Study of Art, Archaeology and Cultural Heritage. 2006; 1(C): $173-203$. DOI: $10.1016 /$ S1871-1731(06)80006-0

13- Dwivedi RS. Lead Exposure alters the drug metabolic activity and the homeostasis of essential metal ions in the lenticular system of rat. Environ Pollut. 1996; 94(1): 61-6.

14- Papanikolaou NC, Hatzidaki EG, Belivanis S, Tzanakakis GN, Tsatsakis AM. Lead toxicity update. A brief review. Med Sci Monit. 2005; 11(10): RA329-36.

15- Bellinger DC. Teratogen update: lead and pregnancy. Birth Defects Res A Clin Mol Teratol. 2005; 73(6): $409-20$. DOI:10.1002/bdra.20127

16- Ettinger AS, Hu H, Hernandez-Avila M. Dietary calcium supplementation to lower blood lead levels in pregnancy and lactation. J Nutr Biochem. 2007; 18(3): 172-8. doi: 10.1016/j.jnutbio.2006.12.007

17- WHO. Environmental Health-Criteria 3. World Health Organization Task Croup on Environmental Health-Criteria for Lead. 1977. Available at: http://www.inchem.org/documents/ehc/ehc/ehc003.htm/ Accessed March 14, 2018

18- Vahid Dastjerdi M, Foroughi M, Mohammadi Moghadam F, Hassanzadeh A, Nourmoradi H. Studying the lead concentration rate in the most popular eye shadow cosmetics in Isfahan city, Iran. Sci Res. J Health Syst Res. 2012; 8(3): 487-92. [Persian]

19- Mohammadi M, Riyahi Bakhtiari A, Khodabandeh S. Determination of Cadmium and Lead Concentration in Cosmetics (Sunscreen, Lipstick and Hair Color). Iran J Health Environ. 2014; 6(4): 481-90. [Persian]

20- Malakootian M, Pourshaaban Mazandarany M, Eskandari M, Pourmahyabady R. Determination of lead concentration in solid and liquid lipsticks available in Iran-Kerman. Hormozgan Med J. 2012; 16(3): 241-6. [Persian]

21- Ayenimo JG, Yusuf AM, Adekunle AS, Makinde OW. Heavy metal exposure from personal care Products. Bull Environ Contam Toxicol. 2010; 84(1): 8-14. doi: 10.1007/s00128-009-9867-5.

22- Volpe MG, Nazzro M, Coppola R, Rapuano F, Aquino RP. Determination and assessments of selected heavy metals in eye shadow cosmetics from China, Italy, and USA. Microchem J. 2012; 101: 65-9. DOI: 10.1016/j.microc.2011.10.008

23- Sainio EL, Jolanki R, Hakala E, Kanerva L. Metals and arsenic in eye shadows. Contact Dermatitis. 2000; 42(1): 510.

24- Aldayel O, Hefine J, Alharbi KN, Al-Ajyan T. Heavy metals concentration in facial cosmetics. Nat Prod Chem Res. 2018; 6(1): 303. DOI: 10.4172/2475-7675.1000303 